\title{
Experimental and numerical modeling to investigate the riverbank's stability
}

\author{
Asad H. Aldefae ${ }^{1}$ (D) Rusul A. Alkhafaji ${ }^{1}$
}

Received: 3 August 2020 / Accepted: 6 January 2021 / Published online: 20 January 2021

(c) The Author(s) 2021 OPEN

\begin{abstract}
The purpose of this paper is to assess the failure mechanism of riverbanks due to stream flow experimentally and numerically to avoid recurring landslides by identifying the most dangerous place and treating them by a suitable method. The experiments and the physical models were carried out to study the failure mechanism of riverbank and evaluation of their stability in two cases: short-term condition and long-term condition flow where three models were tested. The Tigris River (Iraq) is considered as a model in this paper in terms of the applied velocity and modeled soil of the banks it was used at the same characteristics in the prototype scale. Also, a numerical simulation was performed using the FLOW-3D program to determine the velocity distribution and to identify the areas subjected to the high stress levels through the water flow. The obtained results in this paper are inspecting of failure mechanism types that occur under the influence of specific limits of flow velocity, which have shown good compatibility with the type of failure in the prototype scale. In addition to calculating the amount of soil erosion, the failure angle, and the amount of soil settlement at the riverbank model is investigated also. The results of experimental work and numerical simulation were well matched, where the standard error rate for Froude number ranged between (1.8\%-6.6\%), and the flow depth between (2.7\%-6.9\%).
\end{abstract}

Keywords Riverbank · Laboratory flume $\cdot$ Erosion rate $\cdot$ Flow 3D

\section{Introduction}

Riverbank is the part of the river that acts as the responsible part for preventing flood hazards which may lead to many economic and environmental problems such as land inundation, the loss of agricultural areas, and destruction of infrastructures [1]. The study of riverbank stability is considered as one of the most important and complicated studies because of the overlap of several factors with each other which are the geomorphologic factors, hydraulic factors, and geometric factors. Studying riverbank stability and investigating the causes of failure are very important to avoid the recurrence of similar failure [2]. Besides, determining causes of riverbank failure precisely is very important to choose the type of appropriate treatment that meets the hydraulic requirements at the lowest cost [3].

Numerous experimental and numerical studies have been carried on riverbanks stability by previous researchers, where physical models were used and made of different materials and different designs. [4] investigated the stability of the riverbanks using a numerical model that was designed according to 97 days of a result of the impact of seasonal variations on the river and the groundwater level. The numerical model consists of a river and groundwater, the modeling is carried out in the period of lower river level and an increase in groundwater pressure. The results of the numerical model regarding leakage are similar to the results obtained from field measurements of pressure, taking into account the effect of seasonal changes of the river. The assumed groundwater

Asad H. Aldefae, asadaldefae@uowasit.edu.iq | 'Department of Civil Engineering, Faculty of Engineering, Wasit University, Wasit, Iraq. 
heights are used to perform a slope stability analysis. The results of his study showed decrease in the safety factor by $13-17 \%$ at the end of the specified period. A numerical study was conducted by [5] using Prokon software to find out the most influencing factors on riverbanks stability for four different regions on the banks of Shatt Al-Arab. Four sites were chosen to study the stability of the banks of the river, and the engineering dimensions of those banks were measured, and laboratory tests were conducted for the soil sample, namely cohesion, angle of internal friction, and soil density, for depths $0-50,50-100,100-150$ and 150-200, and calculating shear stress at each Depth. The results showed that the soil type in all sites and at different depths is silty clay, but there is a variation in soil properties. And that all the slopes of the banks taken for the study are stable, but they vary in their degree of stability. The study concluded that the soil cohesion, bank height, flow depth, and groundwater level are the most influencing bank stability. Predictive equations were also derived to determine the stability of the bank. An experimental and numerical study was conducted by [6] to compare the effect of two various materials with three various densities on the stability of the overhanging riverbanks. The experimental results showed good compatibility with the numerical results accomplished using SIGMA/W software which was that the mechanism of toppling failure (the most common failure mechanism). A physical model was designed and manufactured by [7] to measure the erosion function (the relation between the erosion rate and the hydraulic shear stress) as well as sing GeoStudio software to perform a numerical simulation of the slope stability in the case of natural flow and the case of flooding (the safety factor values were close in both cases). An experimental study was carried out by [8] to study the mechanism of the cantilever failure, found that the occurrence of the cantilever failure was preceded by the appearance of the tension cracks on the surface after the erosion occurred at the toe of the bank. Three types of riverbanks treatment were compared (vegetation, gabion, and riprap) by determined the causes of riverbank erosion using a hydraulic mathematical model RAM2 with BSTEM software. The study conducted on the Tigris river in Nu'amania city by [3]. The study consisted of several steps, the first of which was using the mini-jet device to calculate the erosion rates and to find the value of shear stress and erosion coefficient for ten soil samples. The second step is to create two models, one without treatment and the other using two types of treatment, which are riprap and vegetation, using the riverbank stability program. The third step is to prepare two models, one without treatment and the other using three types of treatment, which are riprap, gabion and vegetation cover, using the two-dimensional surface water modeling program. The results concluded that the use of riprap treatment is the best in terms of cost and provision of hydraulic requirements. [9] conducted an experimental study using a horizontal flume to investigate the effect of the angle of slope and water level in the river on riverbank stability. Good results were obtained to predict the stability of the bank. [10] studied the effect of the bed slope and the angle of flow on the transportation of sediment using an acrylic flume by applying different proportions of moisture content The results showed that the collapse volume increases with the increasing the angle of flow and the bed slope when the moisture content was greater than the degree of saturation or less.

In this paper, principles of physical modeling in water engineering are considered to perform the experimental work in the engineering laboratories at University of Wasit to investigate the failure mechanism under both short and long term condition flow as well as dimensional analysis for most influenced parameter to introduce simple empirical equations whereas the numerical modeling is conducted under similar prototype conditions for comparing with the experimental results.

This paper consists of five sections. In the first part, the introduction presents a summary of defining the stability of riverbanks, in addition to mentioning literary reviews on the topic. The second part presents the laboratory work, which includes preparing the used soil sample, determining its properties, conducting soil density calibration, designing the earthen channel model, and conducting a slope stability analysis. Details of numerical simulation are explained in Part Three. In the fourth part, the results of this study are presented and discussed, which include laboratory and numerical results. In the last part, the most important conclusions reached through this study are presented.

\section{Experimental work}

\subsection{Design of flume apparatus and model preparation}

To provide a physical model that simulates natural rivers, a flume apparatus was designed and manufactured. The details of the manufacturing process are explained in a previous by [11]. The dimensions of the flume were designed according to the amount of flow velocity that these dimensions accommodate, after considered the Tigris river (One of the largest rivers in the world) in the city of Wasit as a case for this study, and obtaining the velocity data in that region from a previous study [12]. The soil that was used in the physical modeling preparation is a specimen of the Tigris riverbank soil, the specimens were collected from both sides of the riverbanks close to Al-Kut 
barrage and then transported to the laboratory for model preparation under similar field conditions (i.e. density and moisture content). The soil was stored within plastic bags in order to maintain the moisture content, then the laboratory tests were carried out to identify the basic properties of the soil sample. The tests included Atterberg limits (liquid limit and plastic limit), specific gravity, particle size distribution by wet sieving (sieve analysis and hydrometer analysis), field density, soil compaction, and direct shear test. Later on, the soil was classified according to the Unified Soil Classification System (USCS). The earth channel is designed in the form of the section and dimensions that accommodate limits of required velocity. In addition to conducting the soil density calibration to achieve the same field density in the model, because the soil type is a fine grain particle soil and it is not possible to change the soil properties in physical modeling because it is under the influence of the critical stress threshold of the grains and that any change leads to a change in the output. After the above mentioned steps, which will be explained in detail in the next paragraphs, the boundary conditions of the flume have been tested by conducting a preliminary examination to ensure that these dimensions accommodate the expected failure in the channel sides. Table 1 illustrates the physical properties of the used material.

\subsection{Calibration of soil density}

Calibration is the process of providing an instrument to achieve the result of a sample within an acceptable range. The laboratory calibration of the soil density was carried out using a steel container with certain dimensions of $44 \mathrm{~cm}$ length, $15 \mathrm{~cm}$ width, and $22.5 \mathrm{~cm}$ height. The selection of the container of this relatively large size was considered for the purpose of allowing the soil to behave as in the infinite medium [13]. The soil was placed within the template in three layers, and each layer was compacted

Table 1 Physical properties of used material

\begin{tabular}{ll}
\hline The property & Grade \\
\hline Liquid limit & 33.29 \\
Plastic limit & 26.31 \\
Plasticity index & 6.98 \\
Specific gravity, $G_{s}$ & 2.67 \\
USCS & $\mathrm{ML}$ \\
Maximum dry density, $\gamma_{d \max }\left(\mathrm{KN} / \mathrm{m}^{3}\right)$ & 16.2 \\
Field density $\left(K N / \mathrm{m}^{3}\right)$ & 15.1 \\
Cohesion force, $C$. (Actual model), $\left(K N / \mathrm{m}^{2}\right)$ & 25.2 \\
Friction angle, $\emptyset$. (Actual model) & 9.17 \\
Cohesion force, $C$. (Non actual model), $\left(K N / \mathrm{m}^{2}\right)$ & 16.7 \\
Friction angle, $\emptyset$ (Non actual model) & 34.3 \\
\hline
\end{tabular}

with a certain number of blows using a small manufactured hammer with a weight of $2 \mathrm{~kg}$. After compaction of the three soil layers inside the container, it was weighted with the soil, and a sample of the soil was taken for the purpose of calculating water content. The same previous procedures were repeated, with increasing the number of blows each time until the required density was achieved, Fig. 1 illustrates the relationship of soil density calibration with the number of blows. The model was prepared inside the flume using the same method mentioned above since the soil was compacted in three layers using the same hammer with number of blows equivalent exactly to what have been achieved from the calibration process to attain the required density (i.e. 32 blows), then a small tube was used for testing the density according to the procedures of the field density test by core cutter method BFC 31,703 , in order to make sure that the required density was achieved correctly which was the same field density of the soil of Tigris riverbank in the site where the soil sample was obtained.

\subsection{Open channel design}

The open channel model inside the flume was designed to be a trapezoidal cross-section in form using manning equation where the design velocity and the normal depth of specified discharge were calculated [14]. The design velocity that was required to be achieved is Tigris river velocity which was obtained from the previous study conducted by [12]. The design was based on the maximum discharge $Q$ of the used pump which is $1300 / \mathrm{min}$. The side slope $S_{s}$ was determined depending on the type of the soil used in the modeling which is determined as 0.5 horizontal to 1 vertical [15], the bed slope $S_{0}$ and the width of the channel bed $B$ were assumed to be 0.005 and $0.2 \mathrm{~m}$, respectively. The value of manning coefficient $n$ assumed to be 0.025 which is the value usually assumed for design purposes. By applying the Manning Eq. 1, the flow depth

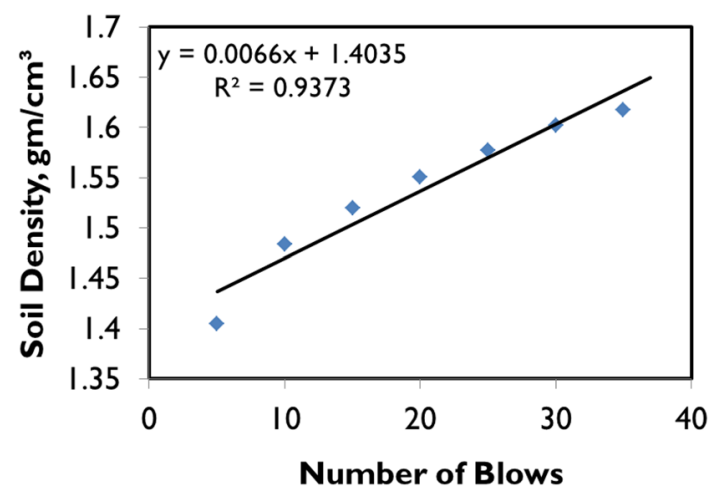

Fig. 1 Calibration of soil density relationship with number of blows 
was calculated and then used to calculate the area of the section, from which the velocity was computed by applying the continuity equation. Then the manning equation was applied again to verify the accuracy of $n$ value, depending on the velocity value and the flow depth. The channel section is designed in a trapezoidal shape because it is closer to the shape of the river section in fact, as illustrated in Fig. 2

Now applying manning equation, Eq. 1 , and for $n=0.025$ :

$Q=\frac{1}{n} * R_{h}^{2 / 3} * S^{1 / 2} * A$

$y=0.15 m$, Aand $P=0.041 \mathrm{~m}^{2}$, and $0.535 \mathrm{~m}$, respectively, hence $R_{h}=0.077 \mathrm{~m}$. where $R_{h}$ is the hydraulic radius which calculated according to Eq.

$R_{h}=\frac{A}{P}$

where $A$ is the area of the trapezoidal section, $P$ is the wetted perimeter and are calculated using Eqs. 3 and 4 respectively.

$A=(B+Z y) y$

$P=B+2 y \sqrt{1+Z^{2}}$

By applying the continuity Eq. 5, the velocity was obtained $(0.52 \mathrm{~m} / \mathrm{sec})$.

$Q=v * A$

The assumed value of $n=0.025$ was checked by applying the value of velocity and flow depth in the Eq. 1, that found to be 0.024 , not equal to the assumed value of

(a)

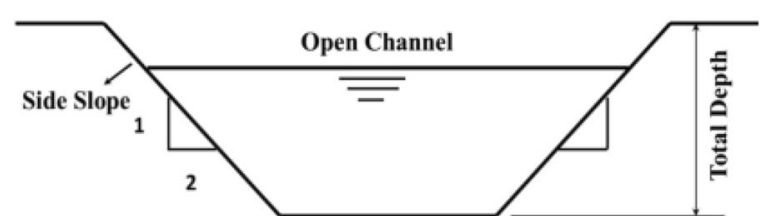

(b)

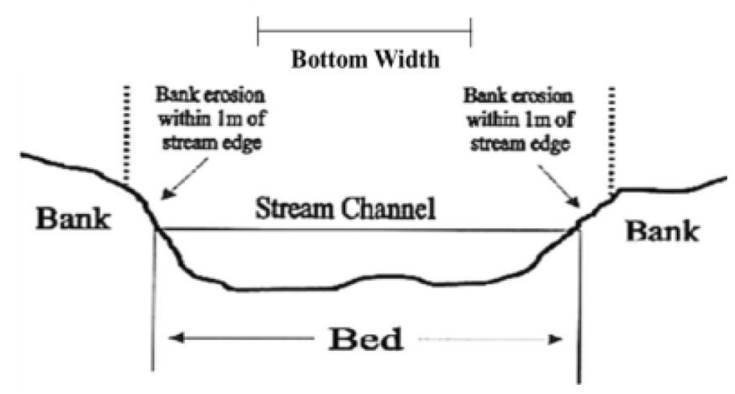

Fig. 2 a Designed channel section, b Natural river section (Turyk et al. 2019) $n=0.025$, so the same procedures are repeated using the new value of $n=0.024$, according to which the resulted value of $y=0.14 \mathrm{~m}$, hence $R_{h}=0.076 \mathrm{~m}$, and the velocity calculated from the continuity equation $v=0.53 \mathrm{~m} / \mathrm{sec}$, then applying Manning equation again using the new value of the velocity in order to calculate the new value of $n=0.0238 \cong 0.024$.

\subsection{Similitude between the model scale and prototype}

The dynamic similarity between two systems occurs when all kinematic parameters are the same and therefore all corresponding forces will be equal in both systems. In this paper, since the phenomenon of the free surface is affected by gravity, the application of Froude model law is ideal to find the model velocity that corresponding to river velocity (i.e. Froude number of the model is equal to Froude number of the prototype) [16].

$F r_{m}=\frac{v_{m}}{\sqrt{g L_{m}}}=F r_{p}=\frac{v_{p}}{\sqrt{g L_{p}}}$

where $F r_{m}, v_{m}, L_{m}$ are the Froude number, velocity, and length of the model respectively. $F r_{p}, v_{p}, L_{p}$ are the Froude number, velocity, and length of the prototype. $g$ is the gravitational acceleration. The length is represented here by the flow depth $y$ according to the $\pi$-group that represents $F r$ which obtained from the dimensional analysis in this study. From Eqs. 4 and 5, the obtained velocity of the model is that $(0.13 \mathrm{~m} / \mathrm{s})$ which corresponding to the highest velocity of the Tigris River $(0.6 \mathrm{~m} / \mathrm{s})$ according to the adopted data in this study [12].

\subsection{Slope stability analysis}

The side slope of the designed channel was testified by slope stability analysis in order to calculate the factor of safety in static condition using the slices method. In this method, the failure surface is imposed as an arc of a circle as mentioned previously [17] where the center of the circle is forced at a certain point. The slipping area is divided into several slices that equal in width, and the horizontal distance of the arc length is divided into equal spaces representing the number of slices. Then a line was drawn, extending from the center of the circle to the center of the slice base which represents the resistance force $\mathrm{N}$, and drawing a vertical line from the same point representing the weight of the slice $W$, which is the results of multiplying the area of the slice by the soil density, $\left(W_{n}=\right.$ Area $\left.* \gamma\right)$. The driving force is represented by line $T$ which is vertical on the $\mathrm{N}$ and extends towards $\mathrm{W}$, as shown in Fig. 3. The length of each slice was measured manually using a 


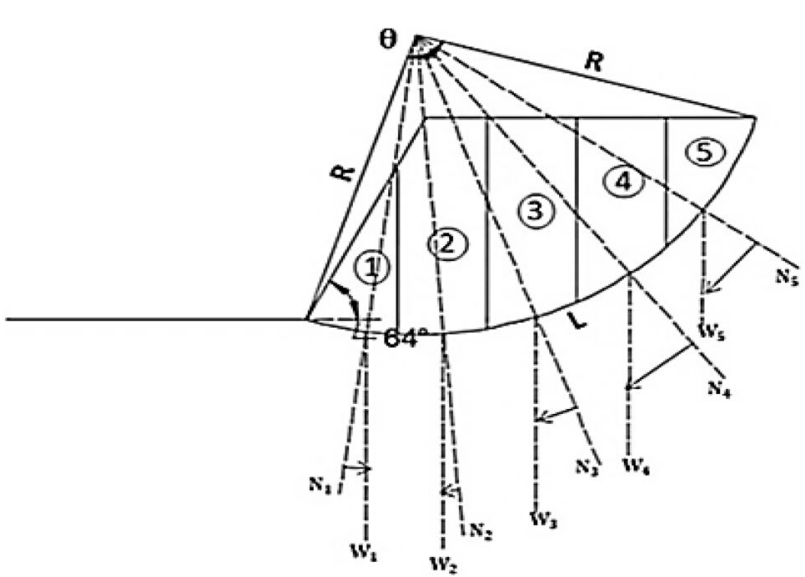

Fig. 3 Representing of N, W, and T on the failure surface

graph paper, and by using a certain scale. The same steps were repeated three times, each time the center of the circle was assumed at a certain point, in the first case the values of the angle $\theta$ and the radius $R$ were $91^{\circ}$ and $6 \mathrm{~m}$ respectively, in the second case, $\theta=64^{\circ}, R=8 \mathrm{~m}$, and in the third case, $\theta=51^{\circ}, R=10 \mathrm{~m}$, the calculations of each case are illustrated in Table $2 \mathrm{a}, \mathrm{b}$, and c respectively.

After the values of $\mathrm{N}, \mathrm{W}$, and $\mathrm{T}$ are obtained, they are applied in the equation of the safety factor, all the calculations are shown below:

$F . S=\frac{C\left(R \theta \frac{\pi}{180}\right)+\sum N(\tan \emptyset)}{\sum T}$

where $C=25.2 \mathrm{KN} / \mathrm{m}^{2}$ is the soil cohesion, $R$ is the radius of the circle, $\theta$ is the angle that opposite the failure surface, and $\emptyset=9.17^{\circ}$ is the angle of friction between soil particles. where $\gamma=15 \mathrm{KN} / \mathrm{m}^{3}$ is the soil density, $\alpha_{n}$ is the angle between $N$ and $W$. Later on, safety factor is determined by applying the equation and it was noticed ranged between 3.92 and 3.6 when $\theta$ ranged between 90 and 51 and $\mathrm{R}$ between 6 and $10 \mathrm{~m}$. This means the design is stable.

\subsection{Experimental procedures}

Three model tests were carried out in this paper, all of them were similar in most of the preparation procedures,

Table 2 Calculations of safety factor

\begin{tabular}{|c|c|c|c|c|}
\hline Slice no & $\begin{array}{l}W=\text { Area } * \gamma \\
(K N / m)\end{array}$ & $\alpha_{n}$ & $\begin{array}{l}T=W_{n} \sin \alpha_{n} \\
(K N / m)\end{array}$ & $\begin{array}{l}N=W_{n} \cos \alpha_{n} \\
(K N / m)\end{array}$ \\
\hline 1 & 37.7 & 7 & -4.59 & 37.4 \\
\hline 2 & 57 & 4 & 3.97 & 56.86 \\
\hline 3 & 60 & 19 & 19.53 & 56.73 \\
\hline 4 & 47.6 & 36 & 27.97 & 38.5 \\
\hline \multirow[t]{2}{*}{5} & 29.3 & 51 & 22.77 & 18.43 \\
\hline & & & $\Sigma_{T}=69.65$ & $\Sigma_{N}=207.92$ \\
\hline Slice No & $\begin{array}{l}W=\text { Area } * \gamma \\
(K N / m)\end{array}$ & $\alpha_{n}$ & $\begin{array}{l}T=W_{n} \sin \alpha_{n} \\
(K N / m)\end{array}$ & $\begin{array}{l}N=W_{n} \cos \alpha_{n} \\
(K N / m)\end{array}$ \\
\hline 1 & 33.2 & 3 & 1.73 & 33.15 \\
\hline 2 & 49.5 & 11 & 9.44 & 48.59 \\
\hline 3 & 49.9 & 23 & 19.49 & 45.93 \\
\hline 4 & 36.8 & 35 & 21.1 & 30.14 \\
\hline \multirow[t]{2}{*}{5} & 21.4 & 46 & 15.39 & 14.86 \\
\hline & & & & $\Sigma_{N}=172.67$ \\
\hline Slice No & $\begin{array}{l}W=\text { Area } * \gamma \\
(K N / m)\end{array}$ & $\alpha_{n}$ & $\begin{array}{l}T=W_{n} \sin \alpha_{n} \\
(K N / m)\end{array}$ & $\begin{array}{l}N=W_{n} \cos \alpha_{n} \\
(K N / m)\end{array}$ \\
\hline 1 & 32.6 & & & 32.28 \\
\hline 2 & 47.6 & & 13.91 & 45.52 \\
\hline 3 & 46.5 & 25 & 19.65 & 42.14 \\
\hline 4 & 33 & 34 & 18.45 & 27.35 \\
\hline \multirow[t]{2}{*}{5} & 18.6 & 44 & 12.92 & 13.37 \\
\hline & & & $\Sigma_{T}=69.46$ & $\Sigma_{N}=160.66$ \\
\hline
\end{tabular}


except that the first model was an actual model, in which the soil that used was $100 \%$ natural soil from Tigris riverbank soil and similar field density is achieved. The second model was the non-actual soil model, as the soil type was changed by using $50 \%$ natural soil $+50 \%$ sand. The test period for each of the above models was $5 \mathrm{~h}$ (short-term flow duration). The third model was also an actual model, but the test period was $24 \mathrm{~h}$ (long-term flow duration). In the actual physical models, the soil was used in its natural state (i.e. the soil was not sieved and no water was added, then the following procedures were done:

1. The soil was laid in layers with the compacting of each layer of a certain proportion using a specially designed hammer to achieve the required density, as mentioned earlier in this paper. The signs were placed on the flume walls to determine the dimensions of the channel that was designed in advance.

2. For controlling purposes, achievement of the required side inclination angle, a wooden plank extending along the length of the flume was used and fixed from the sides during soil placement and compression, and then removed after completion of the process (i.e. Fig. 4a).

3. For controlling purposes, the flow turbulence at the beginning of the channel, a treatment was used by the stone cladding extending approximately half a meter (i.e. Fig. 4b).

4. Two LVDTs were installed in two different positions to measure the vertical displacement which represents the settlement in riverbank.

5. Flow velocity was measured using a mini-water flow meter device of precision $\pm 2 \%$.

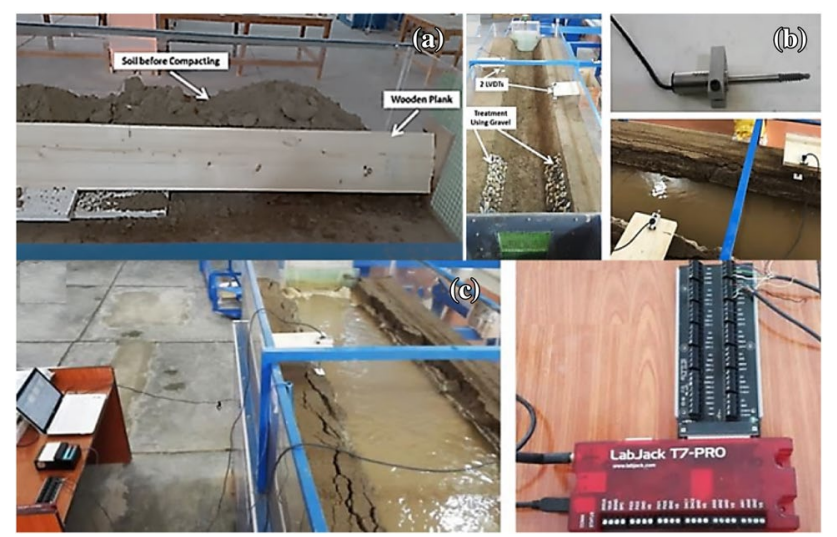

Fig. 4 Experimental procedures, a the side slope construction using a wooden plank, $\mathbf{b}$ the treatment at the beginning of the channel, and the 2 LVDTs positions, $c$ general format of the binding system and the Data-Logger device
5. The behavior of the failure mechanism was recorded by taking pictures and short videos using a high-speed camera.

Figure 4c shows the overview of the binding system, where the LVDTs are connected to the Data-Logger device which in turn transfers data to the computer.

In the preparation of non-actual model, the sand was sieved using a sieve with a diameter of $2 \mathrm{~mm}$, and then mixed with natural soil in equal quantities with the addition of an appropriate amount of water to control the preparation of the model, the mixing process was done using the mixing device. After that, the same procedures mentioned above were repeated.

\subsection{Test program}

The test program was established to study and investigate the failure mechanism that occurs in natural riverbanks, and the amount of soil settlement of the riverbank due to the effect of water flow velocity with different flow periods. Three models were tested; the first model called an actual model, $100 \%$ natural soil of the Tigris riverbank's soil was used (which was considered as a real model for this study). The applied velocity was within the range of the Tigris river velocity, where the test was started with low flow velocity and increased gradually at different time intervals. The flow depth was measured with each applied velocity. The failure mechanism was recorded by taking pictures and short videos using a high-speed camera. Occurrence of the bank's collapsibility has been inspected carefully during the water flow due to appearance of the cracks on the surface, where the width of failure block and the depth of the crack were measured for each location of the crack. Then, the angle of failure depending on these variables is calculated. For this model, the test period was $5 \mathrm{~h}$ (short-term flow duration). This period is selected according to [18]. In the second test model (non-actual model), the same conditions of the first model were applied except that the soil type was changed using ( $50 \%$ natural soil $+50 \%$ sand). This sand is widely used by others [19]. The third test model was also similar to the conditions of the first model except that the test period was $24 \mathrm{~h}$ (long-term flow duration), this period was selected according to [20], who choose $36 \mathrm{~h}$, but here the period was reduced to $24 \mathrm{~h}$ due to the difficulty of digital data saving for a longer.

\section{Numerical simulation}

FLOW-3D software also called computational fluid dynamics CFD which is the science of describing fluid movement through non-linear equations of the second order, where 
the basis of work of this software is to solve the equations of fluids movement through digital techniques developed specifically for this purpose. FLOW-3D enables the application of many fluid flow phenomena by providing many options. The numerical model consists of a set of interrelated elements called cells, the cell group is called a network, which is the numerical area that represents the original physical space. FLOW-3D provides a free surface simulation model where the free surface is considered to be one of the outer boundaries of the liquid, although it is difficult to provide such a model in any computational environment due to the changes in flow parameters such as velocity, pressure, and density. The method of the volume of fluid VOF is used in FLOW-3D software for the purpose of free surface simulation.

In the numerical simulation of turbulent flow in open or uncompressed surfaces, the governing equations are the continuity equation and momentum conservation equation, which known as Navier-Stock equation, mathematically, these equations represent mass conservation equation and momentum conservation equation.

\subsection{Geometry and meshing}

The geometric shape of the designed channel was drawn using AutoCad-3D Modeling, the file was then exported to a stereo lithographic format (stl) as shown in Fig. 5a, which is the format that FLOW-3D software is dealing with. After opening the file in FLOW-3D software the appropriate grid was created. In FLOW-3D software the numerical model is divided into a grid of rectangular cells. Increasing the number of network elements by reducing the element's spacing gives a better representation of reality, but this takes longer time during the running, so the user must determine the appropriate number of elements that meet these requirements. Rectangular networks are characterized accurately and stability of numerical solutions through the accurate representation of the original physical problem which are considered the basis used in the development of the finite difference method and the finite volume method. The finite difference method is based on the oldest methods used in numerical solutions of differential equations, Taylor expansion and the

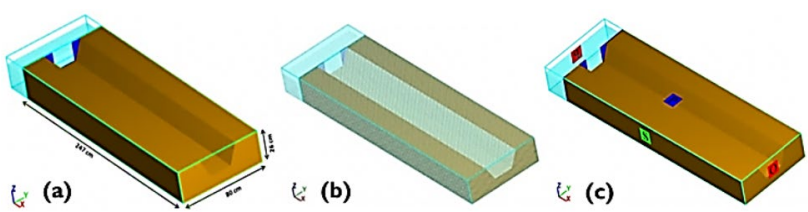

Fig. 5 Numerical model, a model dimensions, b mesh generation, $\mathbf{c}$ boundary conditions straightforward application of the definition of derivative, which was developed by Euler in 1768. The finite volume method is based on the equations of fluids movement [21]. There are three types of mesh in FLOW-3D software, basic mesh, multi-block mesh and confirming mesh. The type of mesh used here is the basic mesh. This type requires determining the total number of elements after a number of attempts. At each time, the number of elements was increased until the optimal number was obtained. FLOW3D software provides the FAVOR technique, through which the selected number of cells can be tested if either it is appropriate to represent the geometric shape of the model or not. This indication represent the proportion of the fractional area to the volume fraction of the elements by calculating the fractions of the open area (AFT, AFR, $A F B$ ) on the element surfaces along with the fraction of open volume (VF) and rebuilds the geometry depending on these parameters. This technique provides a simple and delicate way to represent the complex surfaces. Fig. $5 \mathrm{~b}$ illustrates the mesh generation by FAVOR.

\subsection{Boundary and initial conditions}

The equations that govern fluid flow movement depend on the boundary conditions and initial conditions of the model, so the conditions of the numerical model must correspond well to the actual conditions of the physical model. In this paper, the boundary conditions of the numerical model were defined as (i) Upstream boundary (X-min), Stagnation Pressure (P); (ii) Downstream boundary (X-max), Outflow (O); (iii) Side boundary (Y-min, Y-max), Symmetry (S), means the same type of the component material, which is packed sediment; (iv) Bottom boundary (Z-min), Symmetry (S) and (v) Top boundary (Z-max), Pressure $(p)$.

At the initial conditions, all of the time-dependent variables are equal to zero, therefore there was no flow. The fluid was at its initial region at the upstream of the channel, as shown in Fig. $5 \mathrm{c}$.

\subsection{Physics and material properties}

FLOW-3D software has many physics options, selecting some of these options depends on the nature of the case that required to be simulated. In this paper, the gravity option was activated in the negative vertical direction $\left(-980 \mathrm{~cm} / \mathrm{sec}^{2}\right)$, the option of viscosity and turbulence was activated, where the Newtonian viscosity was applied with the renormalized group RNG turbulence model. The density option was activated as a function for the rest of the variables. Finally, the option of sediment scour, this option requires the definition of some of the material variables of the used model which are the diameter of particles and 
the density, while the rest of the variables were kept the same.

Material properties include the properties of the used fluid. FLOW-3D software provides ready options for some liquids that can be used directly, in this study water with $20^{\circ} \mathrm{C}$ was used, then an option of using fluid database was selected as this option specifies the properties of the selected fluid automatically.

\section{Results and discussions}

\subsection{Experimental results}

The experimental work included three models test. In each model test, the applied velocity at the beginning of the test was $0.1 \mathrm{~m} / \mathrm{sec}$, which is roughly equivalent to the highest velocity of the Tigris river according to the field data adopted in this study [12]. The change in flow depth with the velocity change was measured at different time intervals to be used subsequently to calculate the erosion rate. The development of tension cracks and the failure mechanism of the banks were observed and recorded, along the test period. In addition, measuring the proportion of soil settlement that occurs in the banks of two different locations was also discussed. In the next paragraphs, each one of the parameters mentioned above will be presented and discussed in detail.

\subsubsection{Erosion rate}

Erosion occurs when the amount of the governed shear stress is greater than the critical shear stress. In the experimental test, the velocity that applied initially was $(0.1 \mathrm{~m} / \mathrm{sec})$ as previously mentioned and the flow depth was up to $(12 \mathrm{~cm})$. After a period of operating, the flow depth decreased significantly due to change in the channel segment as a result of drifting the particles with the flow. To maintain an effective depth of flow, the discharge was increased gradually which in turn leads to a little increase in velocity, but the flow depth was still less than the previous depth due to the morphological changes in the channel section, as will be clarified in the subsequent sections.

The first model is the actual model (i.e. 100\% natural soil from the Tigris Riverbanks) with short-term flow duration $(5 \mathrm{~h}$.), the second model is the non-actual model (i.e. $50 \%$ natural soil $+50 \%$ sand) with short-term flow duration ( $5 \mathrm{~h}$.), and the third model is also an actual model but with long-term flow duration ( $24 \mathrm{~h}$.).

Reference source not found. $a, b$ and c illustrate the hydraulic calculations of the three models. Depending on the measured velocity $(v)$, measured flow depth $(y)$ and the channel bed width $B$ which assumed to be constant, all hydraulic parameters were calculated. The cross sectionalarea $A$ and the wetted perimeter $P$ were calculated using the equations of the trapezoidal section (see Eqs. 3 and 4). Hence, the hydraulic radius $R_{h}$ was calculated according to Eq. 2. Water surface width $T_{w \prime}$ and the hydraulic depth $D$ were calculated from Eqs. 8 and 9, respectively.

$T_{w}=B+2 Z y$

$D=\frac{A}{T}$

In order to specify whether the flow is laminar or turbulent, Reynold number should be calculated, which represents the proportion of viscous and inertial forces. The flow is laminar when Reynold number is less than 2300 and turbulent when it is greater than 2900 . Reynold number $R e$ was calculated according to Eq. 10, Froude number Fr was calculated using Eq. 11.

$R e=\frac{\rho v D}{\mu}$

$F r=\frac{v}{\sqrt{g D}}$

The erosion rate was calculated using the Eq. 12 that was developed by $[22,23]$. This equation used to predict the erosion rate in $(\mathrm{m} / \mathrm{sec})$ of fine-grained soils, depending on the applied shear stress $\tau_{a}$ (determined by Eq. 13 ) and the critical shear stress $\tau_{c r}$ (determined by Eq. 14) which was depending on the percent of clay in the soil for each model [24]. $\tau_{e}$ can be represents the excess shear stress which is the difference amount between the applied shear stress and critical shear stress.

$\varepsilon=K_{d}\left(\tau_{a}-\tau_{c}\right)^{a}$

$\tau_{a}=\rho g d S$

$\tau_{c}=0.493 \times 10^{0} .0182 P_{c}$

where $\varepsilon$ is the erosion rate $(\mathrm{m} / \mathrm{s}) ; \tau_{a}$ is the applied shear stress (in $P a$ ); $\tau_{c}$ is the critical shear stress (in $P a$ ); $(a)$ is a component commonly assumed equal to $1 ; K_{d}$ is the erodibility coefficient (in $\mathrm{m}^{3} / \mathrm{N}$.s) is calculated from Eq. 15 as a function of critical shear stress [25]; $\rho$ is the density of water $\left(\mathrm{Kg} / \mathrm{m}^{3}\right) ; g$ is the gravity acceleration $\left(\mathrm{m} / \mathrm{s}^{2}\right) ; d$ is the height of water above the midpoint of the section $(m) ; S_{0}$ is the channel slope; $P_{c}$ is the percent clay by weight Table 3 .

$K_{d}=0.2 \tau_{c}^{-0.5}$ 
Table 3 The calculations of the hydraulic parameters and the erosion rate, (a) Model 1, (b) Model 2, (c) Model 3

\begin{tabular}{|c|c|c|c|c|c|c|c|c|c|c|c|c|c|c|}
\hline Time(hr) & $v\left(\frac{m}{s e c}\right)$ & $y(m)$ & $B(m)$ & $A\left(m^{2}\right)$ & $P(m)$ & $R_{h}(m)$ & $T(m)$ & $D(m)$ & $\operatorname{Re}$ & $\mathrm{Fr}$ & $\left.\tau_{\mathbf{a}}(P a)\right)$ & $\tau_{\mathbf{c r}}(P a)$ & $\left.\tau_{\mathbf{e}}(P a)\right)$ & $\varepsilon\left(\frac{m m}{h r}\right)$ \\
\hline 0.000 & 0.100 & 0.120 & 0.200 & 0.031 & 0.468 & 0.067 & 0.320 & 0.098 & 9750.000 & 0.102 & 4.778 & 0.498 & 4.280 & 4.366 \\
\hline 1.000 & 0.115 & 0.110 & 0.200 & 0.028 & 0.446 & 0.063 & 0.310 & 0.090 & $10,405.645$ & 0.122 & 4.434 & 0.498 & 3.936 & 4.016 \\
\hline 2.000 & 0.120 & 0.100 & 0.200 & 0.025 & 0.424 & 0.059 & 0.300 & 0.083 & $10,000.000$ & 0.133 & 4.083 & 0.498 & 3.585 & 3.658 \\
\hline 3.000 & 0.130 & 0.098 & 0.200 & 0.024 & 0.419 & 0.058 & 0.298 & 0.082 & $10,645.168$ & 0.145 & 4.012 & 0.498 & 3.514 & 3.586 \\
\hline 4.000 & 0.140 & 0.095 & 0.200 & 0.024 & 0.412 & 0.057 & 0.295 & 0.080 & $11,158.475$ & 0.158 & 3.905 & 0.498 & 3.407 & 3.477 \\
\hline 5.000 & 0.150 & 0.093 & 0.200 & 0.023 & 0.408 & 0.056 & 0.293 & 0.078 & $11,736.092$ & 0.171 & 3.834 & 0.498 & 3.336 & 3.403 \\
\hline Time $(h r)$ & $v\left(\frac{m}{s e c}\right)$ & $y(m)$ & $B(m)$ & $A\left(m^{2}\right)$ & $P(m)$ & $R_{h}(m)$ & $T(m)$ & $D(m)$ & Re & $\mathrm{Fr}$ & $\tau_{\mathbf{a}}(P a)$ & $\tau_{\mathbf{c r}}(P a)$ & $\tau_{\mathbf{e}}(P a)$ & $\varepsilon\left(\frac{m m}{h r}\right)$ \\
\hline 0.000 & 0.100 & 0.120 & 0.200 & 0.031 & 0.468 & 0.067 & 0.320 & 0.098 & 9750.000 & 0.102 & 4.778 & 0.495 & 4.283 & 4.383 \\
\hline 1.000 & 0.100 & 0.106 & 0.200 & 0.027 & 0.437 & 0.061 & 0.306 & 0.088 & 8764.052 & 0.108 & 4.294 & 0.495 & 3.799 & 3.888 \\
\hline 2.000 & 0.105 & 0.100 & 0.200 & 0.025 & 0.424 & 0.059 & 0.300 & 0.083 & 8750.000 & 0.116 & 4.083 & 0.495 & 3.588 & 3.672 \\
\hline 3.000 & 0.110 & 0.095 & 0.200 & 0.024 & 0.412 & 0.057 & 0.295 & 0.080 & 8767.373 & 0.124 & 3.905 & 0.495 & 3.410 & 3.490 \\
\hline 4.000 & 0.120 & 0.088 & 0.200 & 0.021 & 0.397 & 0.054 & 0.288 & 0.075 & 8946.667 & 0.140 & 3.653 & 0.495 & 3.158 & 3.232 \\
\hline 5.000 & 0.125 & 0.085 & 0.200 & 0.021 & 0.390 & 0.053 & 0.285 & 0.072 & 9040.570 & 0.148 & 3.544 & 0.495 & 3.049 & 3.120 \\
\hline Time $(h r)$ & $v\left(\frac{m}{\sec }\right)$ & $y(m)$ & $B(m)$ & $A\left(m^{2}\right)$ & $P(m)$ & $R_{h}(m)$ & $T(m)$ & $D(m)$ & Re & $\mathrm{Fr}$ & $\tau_{\mathbf{a}}(P a)$ & $\tau_{\mathbf{c r}}(P a)$ & $\tau_{\mathbf{e}}(P a)$ & $\varepsilon\left(\frac{m m}{h r}\right)$ \\
\hline 0.000 & 0.100 & 0.120 & 0.200 & 0.031 & 0.468 & 0.067 & 0.320 & 0.098 & 9750.000 & 0.102 & 4.778 & 0.498 & 4.280 & 4.366 \\
\hline 2.000 & 0.100 & 0.100 & 0.200 & 0.025 & 0.424 & 0.059 & 0.300 & 0.083 & 8333.333 & 0.111 & 4.083 & 0.498 & 3.585 & 3.658 \\
\hline 4.000 & 0.108 & 0.095 & 0.200 & 0.024 & 0.412 & 0.057 & 0.295 & 0.080 & 8607.966 & 0.122 & 3.905 & 0.498 & 3.407 & 3.477 \\
\hline 6.000 & 0.110 & 0.090 & 0.200 & 0.022 & 0.401 & 0.055 & 0.290 & 0.076 & 8363.793 & 0.127 & 3.726 & 0.498 & 3.228 & 3.293 \\
\hline 8.000 & 0.115 & 0.087 & 0.200 & 0.021 & 0.395 & 0.054 & 7 & 0.074 & 8488.563 & 0.135 & 3.617 & 0.498 & 3.119 & 3.182 \\
\hline 10.000 & 0.115 & 0.085 & 0.200 & 0.021 & 0.390 & 0.053 & 0.285 & 0.072 & 8317.325 & 0.137 & 3.544 & 0.498 & 3.046 & 3.108 \\
\hline 12.000 & 0.120 & 0.082 & 0.200 & 0.020 & 0.383 & 0.052 & 0.282 & 0.070 & 8409.362 & 0.145 & 3.434 & 0.498 & 2.936 & 2.995 \\
\hline 14.000 & 0.123 & 0.080 & 0.200 & 0.019 & 0.379 & 0.051 & 0.280 & 0.069 & 8434.286 & 0.150 & 3.360 & 0.498 & 2.862 & 2.920 \\
\hline 16.000 & 0.125 & 0.078 & 0.200 & 0.019 & 0.374 & 0.050 & 0.278 & 0.067 & 8382.194 & 0.154 & 3.286 & 0.498 & 2.788 & 2.844 \\
\hline 18.000 & 0.129 & 0.075 & 0.200 & 0.018 & 0.368 & 0.048 & 0.275 & 0.065 & 8355.682 & 0.162 & 3.174 & 0.498 & 2.676 & 2.730 \\
\hline 20.000 & 0.130 & 0.070 & 0.200 & 0.016 & 0.357 & 0.046 & 0.270 & 0.061 & 7920.370 & 0.168 & 2.985 & 0.498 & 2.487 & 2.538 \\
\hline 22.000 & 0.140 & 0.065 & 0.200 & 0.015 & 0.345 & 0.044 & 0.265 & 0.057 & 7983.962 & 0.187 & 2.794 & 0.498 & 2.296 & 2.343 \\
\hline 24.000 & 0.150 & 0.060 & 0.200 & 0.014 & 0.334 & 0.041 & 0.260 & 0.053 & 7961.538 & 0.208 & 2.601 & 0.498 & 2.103 & 2.145 \\
\hline
\end{tabular}

It can be observed from Fig. 6 (the calculated erosion rate from the experiment), the highest erosion rate occurred at the beginning of the operating (i.e. approximately at the first hour) which was about $(4.3 \mathrm{~mm} / \mathrm{hr})$. In all three models, the erosion rate gradually decreased. The reason for the decreasing in the erosion rate is the reducing of the applied stress which depends directly on the water depth, while the Froude number was increased. Comparing the initial erosion rate between the three models, it turns out to be higher in the second model where the critical shear stress is less than that of the first and the third model, as it contains a proportion of sand, as shown in Fig. 6

The results of the calculated erosion in this paper are very close to the amount of erosion achieved through a laboratory study conducted on samples from the Red River in Manitoba by [7]. Despite the gradual increase of the velocity with time, the erosion rate was decreased

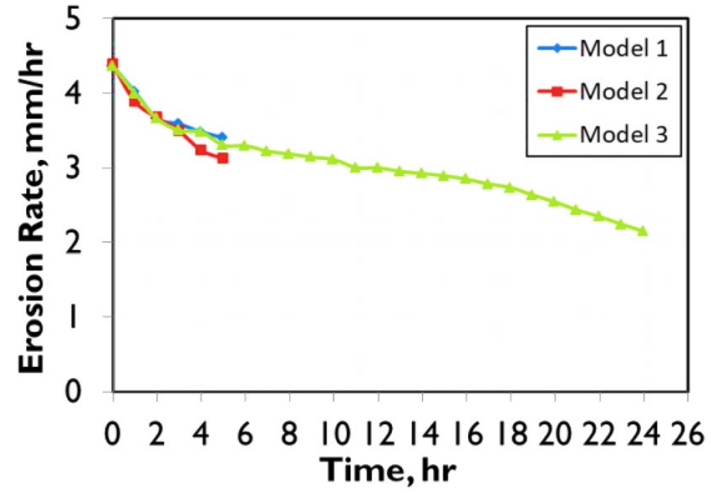

Fig. 6 Degradation of the erosion with time between the three models 


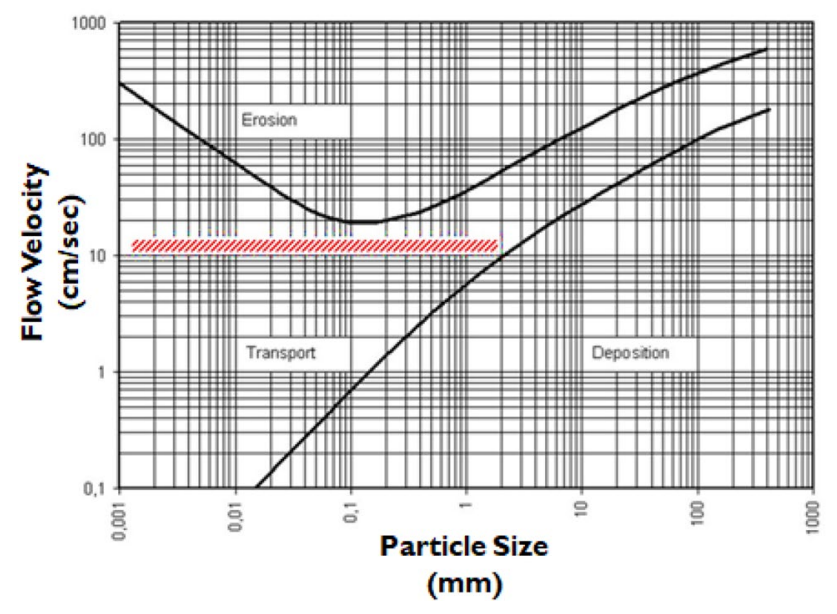

Fig. 7 Representation of the location of soil sample used in the modeling on Hjulstrom curve depending on particle size

and that means that the critical erosion velocity was not achieved. This refers back to Hjulstrom curve, the velocity required for erosion, depending on the size of soil particles that used in the modeling, is approximately equal or more than $(0.2 \mathrm{~m} / \mathrm{sec})$, as shown in Fig. 7

It is clear from the Hjulstrom curve, that the particles which have been scoured from their positions are located within the transportation region. Since they are fine-grain particles, they have transported with the flow with little or no energy, and thus they increase the efficiency of the channel by reducing the friction as mentioned by [26] which was evident by the decreasing of the erosion rate observed.

\subsubsection{Tension cracks}

Tension cracks are one of the most important parameters that affect the stability of the bank since it reduces the shear strength of the soil. The development of tension cracks was evident in the experimental test where it was preceded the failure occurrence. The measurement of the failure block width $B_{w}$, and the tension crack depth $Y$ were obtained from the experimental test, which was used then for calculating the angle of failure $\beta$ by applying the theory presented by [27], Eq. 16. All the parameters of Eq. 16 are illustrated in Fig. 8

$\beta=\tan ^{-1} \frac{\mathrm{H}_{2}}{\mathrm{~B}_{w}+\frac{\mathrm{H}_{3}}{\tan \alpha}}$

Table $4 a, b$, and c illustrate the calculations of the angle of failure for the model 1 , model 2 , and model 3 , respectively depending on the width of failure block and the

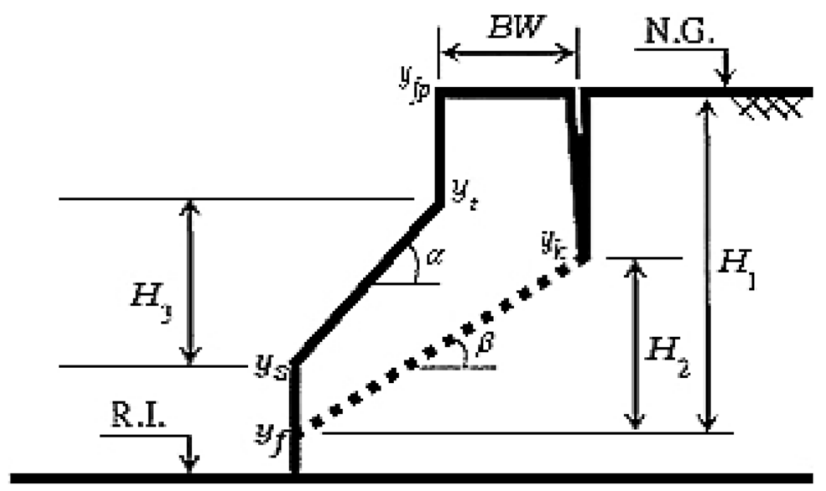

Fig. 8 Parameters used for calculating the angle of failure plane, [27]

depth of tension crack using Eq. 17, where $\left(\alpha=64^{\circ}\right)$ which is the angle before failure.

The settlement results of the selected points at both banks for the first model (the actual model with short-term flow duration), the decrease in the bank height by $65.9 \%$, led to a decrease in the bank angle by $61 \%$, whereas the decrease in the width of the bank width was $75 \%$, as shown in Fig. 9a. The results of model 2 (non-actual model) showed that the bank's angle was decreased by $74.9 \%$, while the decrease in the width and height of the bank were $85 \%$ and $76.5 \%$, respectively, as shown in Fig. $9 \mathrm{~b}$. In model 3 (the actual model with long-term flow duration), decreasing the width and height of the bank by $79.5 \%$ and $58 \%$, the angle of the bank was decreased by $57.6 \%$, as shown in Fig. 9c.

It is clear from the results of the three models that the depth of tension crack was more influential on the angle of failure than the width of failure block. The high rate of decreasing in the bank angle means that the failure size is greater which occurred in the non-actual model as the soil type is non-cohesion soil due to the existence of sand in the specimen. Meanwhile, the tension cracks generated an additional active pressure on the bank and these cracks may lead to a worse state when they still filled with water for a long time as mentioned by [2].

The development of the tension cracks appearance were uneven between the three models, since it was evident in the first model and continued to appear throughout the test period, and was preceded the failure occurrence, as shown in the following section. Fig. 10a shows the tension cracks that appeared in model 1. In the second model, it was more pronounced because the soil contains a half percent of sand (i.e. non-cohesive soil) as shown in Fig. 10b. In the wet state, the sand grains were adhered to each other by a thin layer of water, but upon saturation, the grains became completely surrounded by water which resulted in increased spacing between the grains and thus 
Table 4 The calculations of failure angle

\begin{tabular}{|c|c|c|c|c|c|c|c|}
\hline Time (hr) & $\mathrm{Bw}(\mathrm{cm})$ & $\mathrm{Y}(\mathrm{cm})$ & $\mathrm{H} 2(\mathrm{~cm})$ & $\beta$ & $\beta \%$ & Bw\% & Y\% \\
\hline 1.0 & 15.0 & 5.0 & 11.0 & 25.8 & 40.2 & 31.8 & 68.8 \\
\hline 2.0 & 5.0 & 5.6 & 10.4 & 39.1 & 61.1 & 77.3 & 65.0 \\
\hline 2.0 & 2.5 & 4.0 & 12.0 & 49.3 & 77.1 & 88.6 & 75.0 \\
\hline 3.0 & 5.0 & 3.0 & 13.0 & 45.4 & 71.0 & 77.3 & 81.3 \\
\hline 4.0 & 3.5 & 5.5 & 10.5 & 42.9 & 67.0 & 84.1 & 65.6 \\
\hline 5.0 & 4.5 & 8.0 & 8.0 & 33.0 & 51.6 & 79.5 & 50.0 \\
\hline 5.0 & 4.5 & 3.5 & 12.5 & 45.5 & 71.0 & 79.5 & 78.1 \\
\hline \multirow[t]{2}{*}{5.0} & 3.5 & 9.0 & 7.0 & 31.8 & 49.6 & 84.1 & 43.8 \\
\hline & & & & & 61.1 & 75.3 & 65.9 \\
\hline Time (hr) & $\mathrm{Bw}(\mathrm{cm})$ & $\mathrm{Y}(\mathrm{cm})$ & $\mathrm{H} 2(\mathrm{~cm})$ & $\beta$ & $\beta \%$ & Bw\% & $\mathrm{Y} \%$ \\
\hline 1.0 & 2.0 & 3.0 & 13.0 & 53.0 & 82.8 & 90.9 & 81.3 \\
\hline 1.0 & 3.0 & 4.0 & 12.0 & 48.0 & 75.0 & 86.4 & 75.0 \\
\hline 1.0 & 4.0 & 4.0 & 12.0 & 45.5 & 71.1 & 81.8 & 75.0 \\
\hline 1.0 & 4.0 & 5.0 & 11.0 & 43.0 & 67.2 & 81.8 & 68.8 \\
\hline 2.0 & 3.0 & 2.5 & 13.5 & 51.3 & 80.2 & 86.4 & 84.4 \\
\hline 2.0 & 5.0 & 4.0 & 12.0 & 43.1 & 67.4 & 77.3 & 75.0 \\
\hline 2.0 & 2.0 & 3.0 & 13.0 & 53.0 & 82.8 & 90.9 & 81.3 \\
\hline \multirow[t]{2}{*}{3.0} & 3.0 & 4.5 & 11.5 & 46.8 & 73.1 & 86.4 & 71.9 \\
\hline & & & & & 74.9 & 85.2 & 76.6 \\
\hline Time (hr) & $\mathrm{Bw}(\mathrm{cm})$ & $\mathrm{Y}(\mathrm{cm})$ & $\mathrm{H} 2(\mathrm{~cm})$ & $\beta$ & $\beta \%$ & Bw\% & Y\% \\
\hline 1.0 & 4.0 & 7.0 & 9.0 & 37.3 & 58.3 & 81.8 & 56.3 \\
\hline 1.0 & 5.5 & 5.0 & 11.0 & 39.6 & 61.9 & 75.0 & 68.8 \\
\hline 2.0 & 6.5 & 3.5 & 12.5 & 41.2 & 64.3 & 70.5 & 78.1 \\
\hline 2.0 & 5.0 & 7.5 & 8.5 & 33.6 & 52.5 & 77.3 & 53.1 \\
\hline 3.0 & 2.0 & 9.0 & 7.0 & 35.5 & 55.5 & 90.9 & 43.8 \\
\hline \multirow[t]{2}{*}{4.0} & 4.0 & 8.0 & 8.0 & 34.1 & 53.3 & 81.8 & 50.0 \\
\hline & & & & & 57.6 & 79.5 & 58.3 \\
\hline
\end{tabular}

reduced cohesion. Besides, this process occurred rapidly due to the high permeability which led to increase the pore water pressure [2]. In the third model, the tension cracks were less apparent and did not significantly affect the failure mechanism as seen in Fig. 10c.

\subsubsection{Failure mechanism}

The failure modes that were observed in the results of the experimental test could be discussed according to the decrease in the strength of the soil along the slip surface and the increase in the shear stress [2]. The cracks that were observed on the surface represented the tension in the soil, which exceeded the soil strength. The increase in the shear stress was recognized by three signs, firstly, the excavation at the toe of the bank when the water level was rising due to centrifugal force, so it was highest at the outer bends and as the water comes down due to gravity, there was a helical spiral that occurred which causes erosion at the toe of the bank.
Kind of the failure resulting in this case is called hydraulic failure which was observed in the model 1 as shown in Fig. 11a. Secondly, when the tension cracks filled with water, additional pressure would be generated towards the toe on the slope. If these cracks stay filled with water for long enough time, the pore water pressure would increase and lead to failure. The type of failure resulting in this case is called gravitational failure where the collapse occurs in sliding or toppling of blocks to the channel, which was observed in model 2 as shown in Fig. $11 \mathrm{~b}$. This type of failure is very similar to the failure that occurred in the Tigris River in the flood season due to successive rainstorms in April, 2019 where the river witnessed a significant increase in discharge and the rise in water levels in a manner that had not occurred for many years as shown in Fig. 11c. The last sign was that the sudden drawdown in the water level where the external water pressure provides a positive effect on the slope and when the water level was decreased without decreasing in pore water pressure in the same 

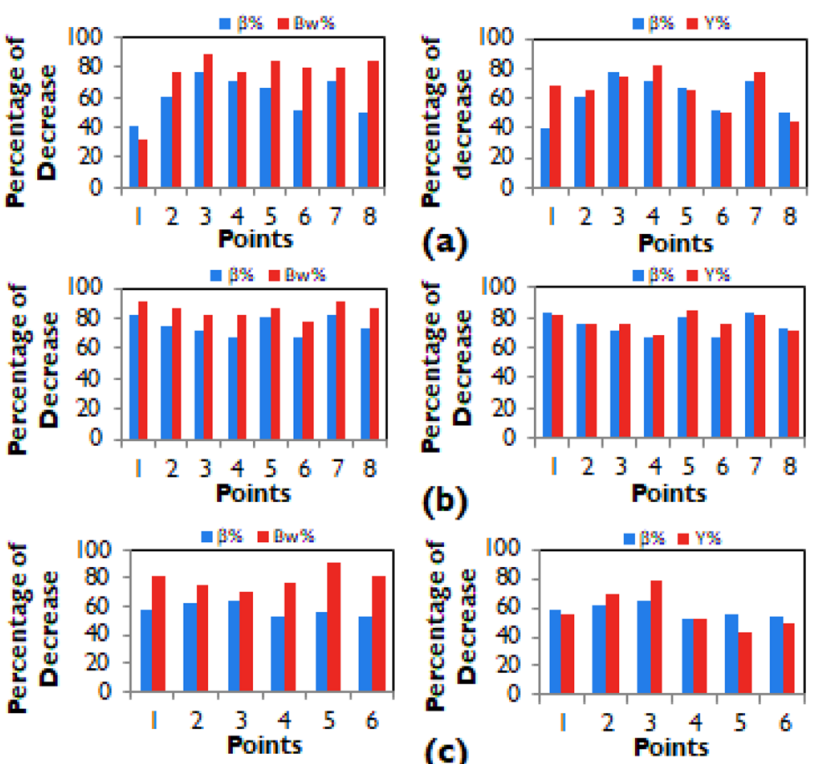

(b)

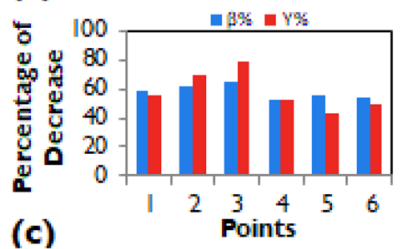

Fig. 9 Representing the percentage of decreasing of the failure angle $\boldsymbol{\beta} \%$ and its relationship with the percentage of decreasing of width and height of the bank, $\boldsymbol{B}_{\boldsymbol{w}} \%$, and $\boldsymbol{Y} \%$, respectively, a Model 1, b Model 2, c Model 3

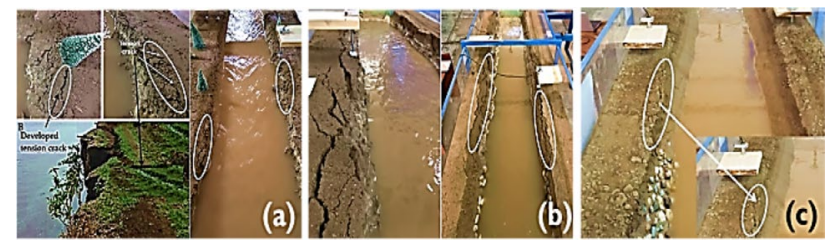

Fig. 10 Development of tension cracks appearance, a Model 1, b Model 2, c Model 3
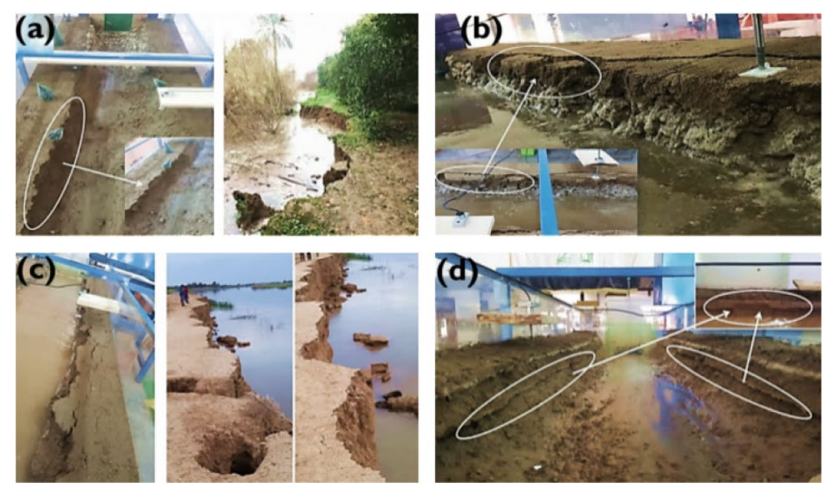

Fig. 11 Failure mechanism observed, a hydraulic failure, comparison between Model 1 and Diyala river, toppling failure, Model 2, c toppling failure, comparison between Model 2 and Tigris river $\mathbf{d}$ Slope failure, Model 3
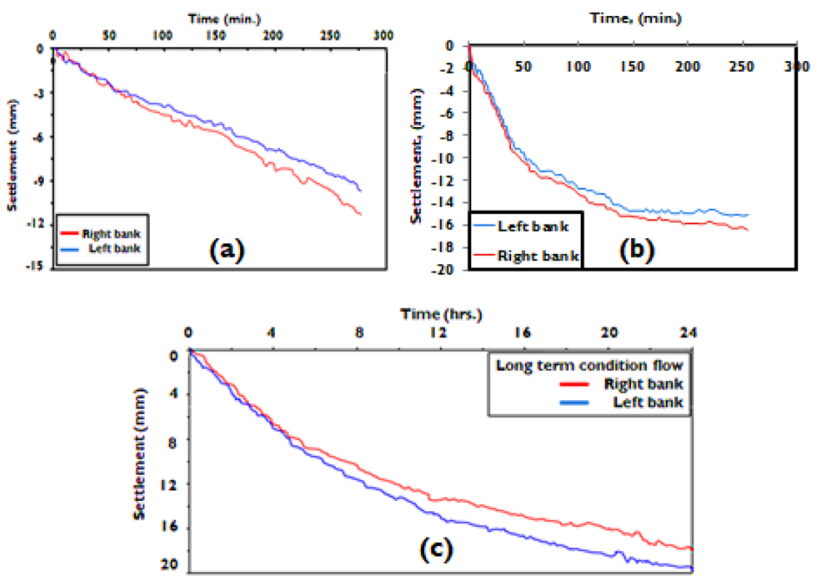

Fig. 12 Representation of the measured soil settlement with time, a Model 1, b Model 2, c Model 3

consistency. The shear stress within the soil increased, which caused the slope failure, as observed in model 3 (Fig. 11d).

\subsubsection{Riverbank settlement}

Soil settlement is the total vertical downward deformation. As mentioned earlier, the cause of failure is the increase in the shear stress within the soil to the extent that exceeds the soil strength. In addition to this, increasing the shear stress causes the compression of soil layers and thus distorts the soil particles, changing locations (reorientation) of the particles, and dissipating water or air from voids that leads to a decrease in pore water pressure, which will affect the soil settlement [28]. This type of deformation was observed in model 1 (short term condition, $5 \mathrm{~h}$.) and model 3 (long term condition flow, $24 \mathrm{~h}$.) and both represent simulating actual models where the amount of settlement was measured using the LVDTs instrument. In model 1 , it was observed that the total settlement at the end of the test ( $5 \mathrm{~h}$.) was around $10.3 \mathrm{~mm}$ and $9.4 \mathrm{~mm}$ at both the right and the left bank respectively as shown in Fig. 12a. In the model 3, the amount of settlement increased significantly, where the total settlement of soil that was observed at the end of the test $(24 \mathrm{~h}$.) was about $17.3 \mathrm{~mm}$ at the right bank, and $19.5 \mathrm{~mm}$ at the left bank, as illustrated in Fig. 12c. Reason of this difference between model 1 and model 3 is that, in the cohesive soils (i.e. the actual models) which have little hydraulic conductivity compared to the non-cohesion soil, the soil settlement needs a longer time to develop [29]. In model 3, the increase in water content due to the increase of flow duration increased the weight of the slope, thus, the settlement amount was higher than the model 1, [2]. In non-cohesive soil with high permeability, excess water is released from the pores rapidly, so the 
soil settlement occurs instantaneously as happened in the model 2 (non-actual model) where the failure occurred at the beginning of the operating, as shown in Fig. 12b. The total settlement at the end of the test $(5 \mathrm{~h}$.), for model 2 was around $15 \mathrm{~mm}$ at the left bank, and $16.4 \mathrm{~mm}$ at the right bank.

\subsection{Numerical simulations results}

\subsubsection{Verification of the FLOW-3D model}

The verification of results for each one of the three models was conducted separately. The values of Froude number and flow depth with the applied velocity were compared between the numerical and experimental results by calculating the percent of variation difference VD\% using Eqs. 17 and 18, for Froude number and flow depth, respectively.
$V D \%=100\left[\left(F r_{e}-F r_{n}\right) / F r_{e}\right]$

$V D \%=100\left[\left(y_{e}-y_{n}\right) / y_{e}\right]$

where $\mathrm{Fr}_{e}$ is the Froude number of the experimental model, $F r_{n}$ is the Froude number of the numerical model, $y_{e}$ is the flow depth of the experimental model, and $y_{n}$ is the flow depth of the numerical model. The calculations of VD\% for the three models are illustrated in the Table $5 \mathrm{a}$, $b$, and $c$ whereas the graphical representation is shown in Fig. 14a, b, and c.

The verification results for model 1 , Table 5 , show that the VD\% of Froude number was ranged from 3.3 to $5.9 \%$, and the VD\% of flow depth was ranged from 2.7 to $5.4 \%$ as shown in Fig. 13a. It is clear from the verification results for the three models that the numerical results

Table 5 Verification results

\begin{tabular}{|c|c|c|c|c|c|c|}
\hline$v\left(\frac{m}{s}\right)$ & $\mathrm{Fr}_{e}$ & $F r_{n}$ & $V D \%$ & $y_{e}(m)$ & $y_{n}(m)$ & $V D \%$ \\
\hline 0.100 & 0.102 & 0.096 & 5.882 & 0.120 & 0.116 & 3.333 \\
\hline 0.115 & 0.122 & 0.118 & 3.279 & 0.110 & 0.107 & 2.727 \\
\hline 0.120 & 0.133 & 0.127 & 4.511 & 0.100 & 0.096 & 4.000 \\
\hline 0.130 & 0.145 & 0.137 & 5.517 & 0.098 & 0.095 & 3.061 \\
\hline 0.140 & 0.158 & 0.151 & 4.430 & 0.095 & 0.090 & 5.263 \\
\hline 0.150 & 0.171 & 0.162 & 5.263 & 0.093 & 0.088 & 5.376 \\
\hline$v\left(\frac{m}{s}\right)$ & $\mathrm{Fr}_{e}$ & $F r_{n}$ & VD\% & $y_{e}(m)$ & $y_{n}(m)$ & $V D \%$ \\
\hline 0.100 & 0.102 & 0.096 & 5.882 & 0.120 & 0.113 & 5.833 \\
\hline 0.100 & 0.108 & 0.104 & 3.704 & 0.106 & 0.101 & 4.717 \\
\hline 0.105 & 0.116 & 0.113 & 2.586 & 0.100 & 0.096 & 4.000 \\
\hline 0.110 & 0.124 & 0.119 & 4.032 & 0.095 & 0.090 & 5.263 \\
\hline 0.120 & 0.140 & 0.134 & 4.286 & 0.088 & 0.085 & 3.409 \\
\hline 0.125 & 0.148 & 0.144 & 2.703 & 0.085 & 0.080 & 5.882 \\
\hline$v\left(\frac{m}{s}\right)$ & $\mathrm{Fr}_{e}$ & $F r_{n}$ & VD\% & $y_{e}(m)$ & $y_{n}(m)$ & VD\% \\
\hline 0.100 & 0.102 & 0.098 & 3.922 & 0.120 & 0.115 & 4.167 \\
\hline 0.100 & 0.111 & 0.106 & 4.505 & 0.100 & 0.096 & 4.000 \\
\hline 0.108 & 0.122 & 0.114 & 6.557 & 0.095 & 0.090 & 5.263 \\
\hline 0.110 & 0.127 & 0.122 & 3.937 & 0.090 & 0.086 & 4.444 \\
\hline 0.115 & 0.135 & 0.128 & 5.185 & 0.087 & 0.081 & 6.897 \\
\hline 0.115 & 0.137 & 0.134 & 2.190 & 0.085 & 0.080 & 5.882 \\
\hline 0.120 & 0.145 & 0.140 & 3.448 & 0.082 & 0.078 & 4.878 \\
\hline 0.123 & 0.150 & 0.144 & 4.000 & 0.080 & 0.075 & 6.250 \\
\hline 0.125 & 0.154 & 0.151 & 1.948 & 0.078 & 0.074 & 5.128 \\
\hline 0.129 & 0.162 & 0.159 & 1.852 & 0.075 & 0.071 & 5.333 \\
\hline 0.130 & 0.168 & 0.163 & 2.976 & 0.070 & 0.067 & 4.286 \\
\hline 0.140 & 0.187 & 0.182 & 2.674 & 0.065 & 0.061 & 6.154 \\
\hline 0.150 & 0.208 & 0.201 & 3.365 & 0.060 & 0.057 & 5.000 \\
\hline
\end{tabular}



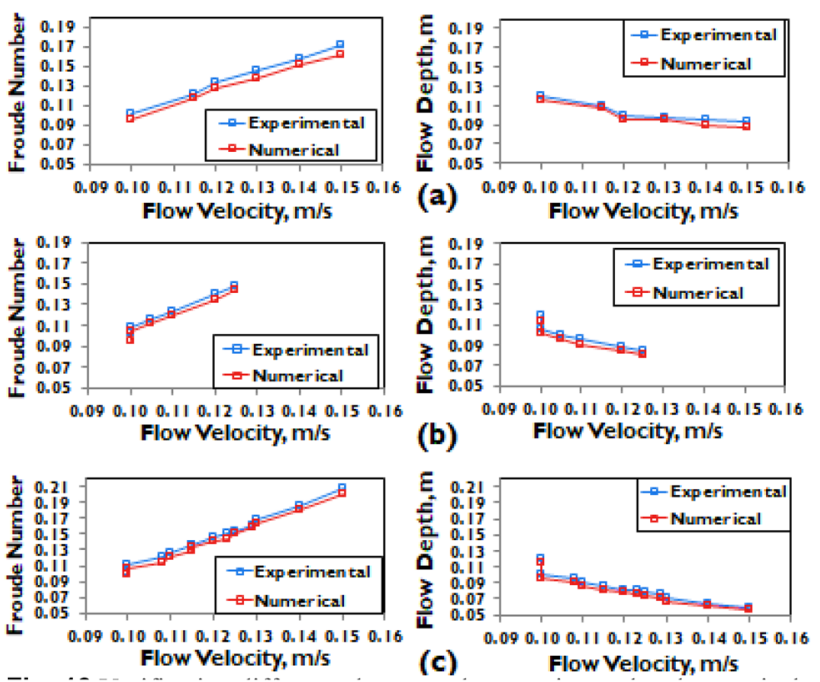

Fig. 13 Verification difference between the experimental and numerical results, a Model 1, b Model 2, c Model 3

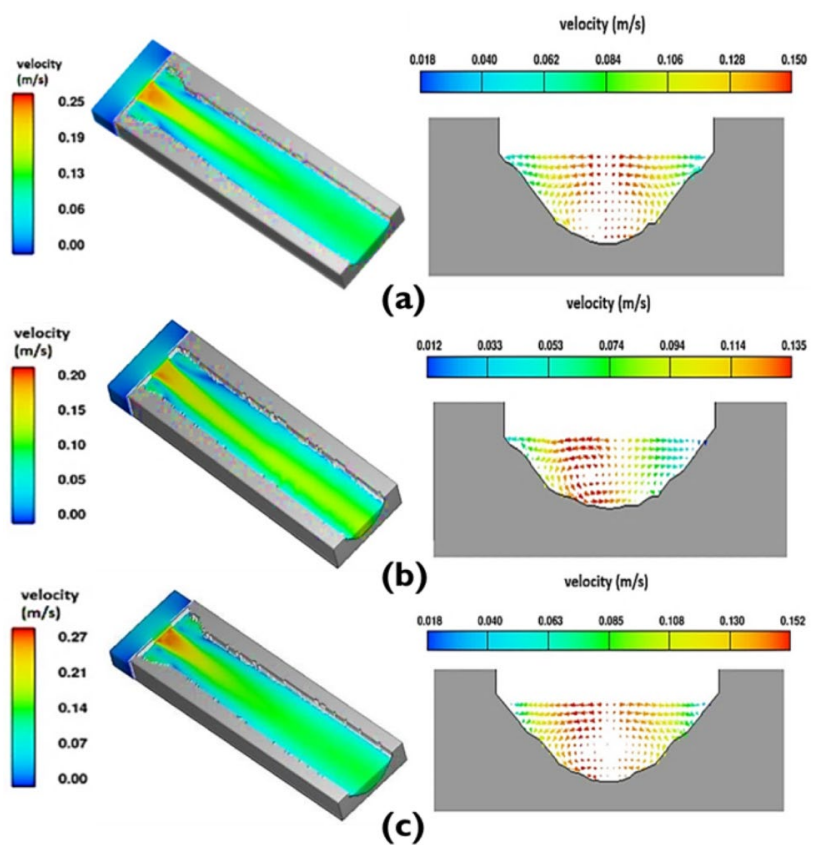

Fig. 14 Velocity distribution within the channel segment; a Model 1, b Model 2, c Model 3

were in good approximation with the experimental results with an acceptable error rate not exceeding $10 \%$.

\subsubsection{FLOW-3D results and discussion}

The purpose of numerical simulation in this paper is to investigate the mechanism of velocity distribution within the channel segment and identify the points that are exposed to higher velocity which will then lead to the occurrence of sediment scour. The results showed that the higher velocity value was in the center of the channel and gradually decreased when approaching boundaries due to increased friction; this is consistent with literary studies as mentioned by [26].

Fig. 14a, illustrates the velocity distribution within the channel segment for mode 1, where the higher velocity value located at the center which equals to about $0.15 \mathrm{~m} / \mathrm{s}$ and decrease gradually towards the boundaries until it reaches about $0.06 \mathrm{~m} / \mathrm{s}$. In model 2 (Fig. 14b), the cross-section of the channel shows that the velocity near the boundaries equal to approximately $0.03 \mathrm{~m} / \mathrm{s}$, while the higher velocity (about $0.13 \mathrm{~m} / \mathrm{s}$ ) occurred near the left bank which led to eroding the toe of the bank. It is clear that the higher velocity was not concentrated in the middle. This phenomenon can be attributed to the occurrence of eddies on one side that resulted from the flow disturbance at the entrance of the channel [15]. Because the soil sample in this model is less cohesive than the first model; the effect of eddies was clear before the equilibrium occurred on both sides. The velocity distribution of model 3 is that $0.15 \mathrm{~m} / \mathrm{s}$ and $0.04 \mathrm{~m} / \mathrm{s}$ at the center and the boundaries of the channel section, respectively as shown in Fig. 14c.

The results of shear stress obtained from the numerical simulation show that the shear stresses are located at the boundaries but vary between the bottom and the banks. In model 1 and model 3, the maximum value of shear stress was located at the banks, while in model 2; it had the maximum amount of shear stress at the bottom, as shown in Fig. 15.

This is due to the fact that in model 1 and model 3 , the depth of sediment that scoured from the bottom was relatively large, so the final shape of the section was rather narrow deep section whereas in model 2 , the sediment deposited at the bottom (because the particle size is rather large as the soil contain $50 \%$ of sand) compared with models 1 and 3, so the final shape of the section in model 3 was closest to the wide shallow section. This explanation is consistent with what was stated by [26], who proved that the greatest amount of shear stress located where the iso-vels. converge from each other. So, in narrow deep

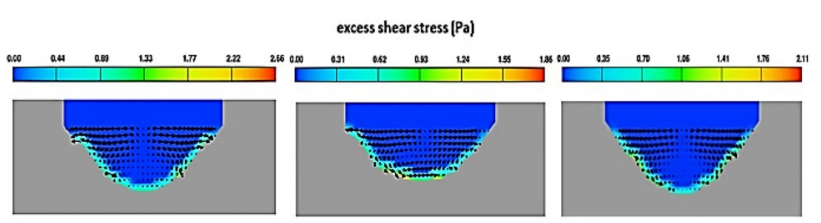

Fig. 15 Excess shear stress locations, a Model 1, b Model 2, c Model 3 
sections, maximum value found at the banks, while in wide shallow sections the maximum value found at the bottom.

\section{Conclusions}

Experimental, and numerical results to investigate the riverbanks stability are performed in this paper. Main conclusions can be summarized as the erosion rate of the bank soil decreases with the decrease of the flow depth despite the gradual increase in velocity, unless it reaches the critical erosion velocity. While it is inversely proportional to the soil cohesion and directly with the internal friction where the highest erosion rate was $(4.383 \mathrm{~mm} / \mathrm{hr})$. occurred in the non-actual model. The erosion rates obtained in this study are well consistent with what was calculated by [7]. The failure angle of the slope is affected by the decrease of the bank height rather than the bank width. The observed types of failure are the hydraulic failure which caused erosion at the toe of the bank in the actual model with shortterm flow duration. The toppling failure due to gravitational effect occurred in the non-actual model, while in the actual model with long-term flow duration the type of failure was a shallow failure. The settlement amount of the bank soil is significantly influenced by the time and the soil cohesion where the highest value of the settlement was $(19.5 \mathrm{~mm})$ in the actual model with long-term flow duration, while the lowest value was $(9.4 \mathrm{~mm})$ in the actual model with short-term flow duration. In the nonactual model with short-term flow duration, the soil settlement was $(16.4 \mathrm{~mm})$ which was very high as the soil type non-cohesion soil. Verification of the results between the experimental model and the numerical model indicates about (1.8-6.6\%) and (2.7-6.9\%) ranged errors for prediction Froude number and flow depth, respectively. This indicates good compatibility between the experimental results and numerical results that conducted using FLOW3D software.

The importance of this study is highlighted by theonclusions that were reached. As the most important characteristic of this work is that the physical model used in the study can simulate natural rivers to some extent by taking into account the influence of hydraulic and geotechnical factors. As the soil sample used in the study for a specific area of the Tigris River, specifically in the city of Wasit in Iraq, with the application of the velocity corresponding to the real river velocity in the same area (after making the similitude between the prototype and the physical model), it means that the same process can be applied to any area. To assess the failures that may occur, and thus the possibility of taking the necessary preventive action.

About future directions for this study, a study is recommended to assess the effect of changing the angle of the side slope on the failure mechanism and the development of tension cracks. Evaluating the meandering effect on riverbank stability is an important study to be taken into consideration. A laboratory study is recommended to determine the effect of rainfall on the amount of soil erosion. There is a need to test different treatment methods for the riverbank by assessing the erosion rates and the size of failure in each case to determine the best treatment type that meets the hydraulic requirements. Some factors affect riverbank stability but cannot be included in the experimental work such as the temperature, wind, and sediment, so it is recommended to conduct a long-term field study g. 2 years in which the cross-section of the river is scanned twice a year, one in the summer season and the other in winter to estimate the actual erosion rates of the river, taking into account that the use of advanced measuring instruments is the key to this study.

\section{Compliance with ethical standards}

Conflict of interest On behalf of all authors, the corresponding author states that there is no conflict of interest.

Open Access This article is licensed under a Creative Commons Attribution 4.0 International License, which permits use, sharing, adaptation, distribution and reproduction in any medium or format, as long as you give appropriate credit to the original author(s) and the source, provide a link to the Creative Commons licence, and indicate if changes were made. The images or other third party material in this article are included in the article's Creative Commons licence, unless indicated otherwise in a credit line to the material. If material is not included in the article's Creative Commons licence and your intended use is not permitted by statutory regulation or exceeds the permitted use, you will need to obtain permission directly from the copyright holder. To view a copy of this licence, visit http://creativecommons .org/licenses/by/4.0/.

\section{References}

1. Taghavi M, Dovoudi M, Amiri-Tokaldany E, Darby SJG (2010) An analytical method to estimate failure plane angle and tension crack depth for use in riverbank stability analyses. Geomorphology 123(1-2):74-83

2. Duncan JM, Wright SG, Brandon TL (2014) Soil strength and slope stability. Wiley, New Jersey

3. AL-Thamiry HA, Taymaa MA (2017) Two-dimensional mathematical model to study erosion problem of tigris river banks at Nu'maniyah. J Eng 23(1):112-135

4. Tutkaluk JM (2000) The effect of seasonal variations in the Red River and upper carbonate aquifer on riverbank stability in Winnipeg University of Manitoba Thesis

5. Albahili NK, Albadran BA, Alhadi SS (2009) The effect of some soil properties on bank stability of Shatt Al- Arab river from Sindibad to Umm Al-Ressass islands. Wadi Al-Rafidian J Marine Sci 24(1):51-64 
6. Samadi A, Amiri-Tokaldany E, Davoudi M, Darby SEJG (2013) Experimental and numerical investigation of the stability of overhanging riverbanks. Geomorphology 184:1-19

7. Jianfar A (2014) Evaluation of erosion rates and their impact on riverbank stability University of Manitoba Thesis

8. Patsinghasanee S, Kimura I, Shimizu Y, Nabi M (2017) Cantilever failure investigations for cohesive riverbanks. Proc Inst Civil EngWater Manag 170(2):93-108

9. Chen $\mathrm{CH}, \mathrm{Hsieh} \mathrm{TY}$, Yang JC (2017) Investigating effect of water level variation and surface tension crack on riverbank stability. J Hydro-Enviromn Res 15:41-53

10. Kharismalatri HS, Ishikawa Y, Gomi T, Sidle RC, Shiraki KJW (2019) Evaluating factors for controlling sediment connectivity of landslide materials: a flume experiment. Water 11(1):17

11. Aldefae AH, Alkhafaji RA, Shamkhi MS, Kumer HQ (2019) Design and manufacturing of flume apparatus to investigate the failure mechanism of riverbanks. Cogent Eng 6(1):1655234

12. Atta ZS (2018) Estimation of roughness coefficient for tigris river (64 Km downstream of kut barrage), University of Wasit Thesis

13. Greacen EL (1981) Soil water assessment by the neutron method. Csiro Australia.

14. Chaudhry MH (2007) Open-channel flow. Springer, New York

15. Chow VT (1959) Open-channel hydraulics. McGraw Hill Book, New York

16. Subramanya K (2011) Fluid mechanics and hydraulic machines: problems and solutions. Tata McGraw Hill, New Delhi

17. Al-Defae AH, Caucis K, Knappett JA (2013) Aftershocks and the whole-life seismic performance of granular slopes. Géotechnique 63(14):1230-1244

18. Song $X, X u G$, Bai Y, Xu D (2016) Experiments on the short-term development of sine-generated meandering rivers. Journal of Hydro-Environment Research 11:42-58

19. Aldefae AH, Shamkhi MS, Alhachami TK (2019) Design and manufacturing of geotechnical laboratory tools used in physical modeling. Cogent Engineering. Cogent Engineering 6(1):1637622

20. Schwartz JS, Palomino AM, Mahalder B (2018) Evaluation and prediction of bridge pier and contraction scour of cohesive river sediments in tennessee report.

21. F. Science, "FLOW_3D v11, user manual," 2014.

22. Partheniades $E$ (1965) Erosion and deposition of cohesive soils. J Hydraul Div 91(1):105-139

23. Hanson GJ, Cook KR (1997) Development of excess shear stress parameters for circular jet testing ASAE Paper vol. 972227

24. Smerdon ET, Robert PB (1961) Critical tractive forces in cohesive soils. Agric Eng 42(1):26-29

25. Hanson GJ, Simon A (2001) Erodibility of cohesive streambeds in the loess area of the midwestern USA. Hydraul Process 15(1):23-38

26. Knighton D (1998) Fluvial forms and processes: a new perspective. Oxford University Press, London

27. Amiri-Tokaldany E, Darby SE, Tosswell P (2003) Bank stability analysis for predicting reach scale land loss and sediment yield. J Am Res Assoc 39:897-910 ((in English))

28. Ahlund R, Ögren O (2016) Pore pressures and settlements generated from two different pile drilling methods. Thesis, Royal Institute of Technology, KTH.

29. Das BM (2006) Principles of geotechnical engineering. Nelson, Canada

Publisher's Note Springer Nature remains neutral with regard to jurisdictional claims in published maps and institutional affiliations. 